\title{
Test Method for the Solubility Model of Physical Blowing Agent of Self-Expanding Polymer
}

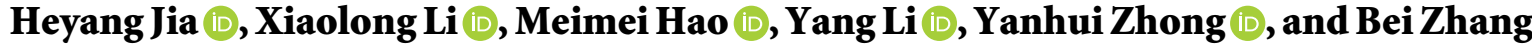 \\ School of Water Conservancy Engineering, Zhengzhou University, 100 Science Avenue, Zhengzhou City 450001, China \\ Correspondence should be addressed to Xiaolong Li; wennuandeshang@hotmail.com
}

Received 12 January 2021; Revised 24 February 2021; Accepted 10 March 2021; Published 26 April 2021

Academic Editor: Isabella Torcicollo

Copyright (c) 2021 Heyang Jia et al. This is an open access article distributed under the Creative Commons Attribution License, which permits unrestricted use, distribution, and reproduction in any medium, provided the original work is properly cited.

\begin{abstract}
This paper aims to present a solubility model of physical blowing agent (PBA) for a kind of commonly used self-expanding polymer on engineering. The self-expanding polymer contains Component A (isocyanate) and Component B (polyhydric alcohol, PBA, water, and catalyst). Component B grout of the polymer, which contains PBA, was heated to measure its temperature and volume variations. Based on the principle of mass conservation and Clapeyron equation, the solubility curve of PBA with respect to temperature was calculated. The solubility curve was then applied to simulate the foaming process. A two-component polymer grout foaming experiment was then carried out to verify the applicability of the measured solubility curve. The simulated changes of temperature and density with respect to time of polymer grout were analyzed and compared with experimental results. The error of both sets of curves is within 5\%, which shows a good agreement among them and proves the feasibility of the solubility model. This study provides a relatively complete test and verification process for the solubility model of PBA, which lays a theoretical foundation for both the polymer grouting diffusion mechanism and engineering application.
\end{abstract}

\section{Introduction}

Grouting is an important method for antiseepage and reinforcement of engineering rock mass. It has been widely used in water conservancy, transportation, mining, and other fields. In recent years, a self-expanding nonaqueous reactive polyurethane grouting material (namely, polymer) and its high-pressure injection technique have developed rapidly [1-5]. Polymer material is a popular process for highway maintenance, tunnel disengaging repair, dam reinforcement, and other engineering fields due to its early strength, high expansibility, and good durability advantages. Polymer grouting has become one of the most characteristic development directions in geotechnical engineering field [6-9].

The research on the diffusion mechanism of polymer grout is significant for grouting design and construction. Compared with the constant density grout such as cement and sodium silicate, which are driven completely by static pressure, the grouting mechanism of self-expanding polymer is more complex. After the polymer grout is injected, chemical reactions occur rapidly. As the reaction goes on, a large amount of heat releases. The PBA gradually vaporizes with the increase of grout temperature, foaming a large number of tiny closed-cell bubbles suspended in the grout liquid. This results in the continuous expansion of grout. The grout was driven to flow as well. Numerical simulation on the chemical reaction process of polymer grout is an important way to study its expansion and diffusion mechanism. Obtaining the PBA solubility is one of the prerequisites for numerical solution of polymer grout expansion process.

Some scholars have conducted researches on the solubility model of PBA. Qian et al. [10] proposed a FloryHuggins solubility model. Tesser et al. [11-14] determined the corresponding parameters of PBA such as $\mathrm{CF} 3 \mathrm{CH} 2 \mathrm{~F}$, $\mathrm{CF} 3 \mathrm{CHF} 2, \mathrm{CF} 3 \mathrm{CH} 3$, and $\mathrm{CH} 2 \mathrm{~F} 2$. Gupta and Khakhar $[15,16]$ established a solubility empirical formula for n-pentane PBA according to a solubility model given by V. K. Gupta. A. J. Rojas et al. presented a temperature- 
related solubility model. Rojas et al. [17, 18] presented relevant parameters of this solubility model for CFC- $11^{\text {a }}$ and HCFC-141b. These papers do not provide the specific test and verification process of the solubility model of PBA; instead, they just give the solubility model and its parameters directly. Therefore, it is necessary to conduct complete test and verification process in combination with different grout types.

In this paper, a two-component polyurethane engineering grouting material was taken as the study object, which involved the following steps:

(1) Component B grout was heated, and the solubility of the PBA of polymer was tested according to the temperature and volume of Component $B$ grout

(2) The solubility model was applied to the simulation of chemical reaction process of polymer; the simulated temperature and density curves with time are obtained

(3) Carry out the foaming experiment of self-expanding polymer grout to obtain its temperature and density changes with respect to time

(4) The applicability of the measured solubility curve was verified by comparing the simulated value in (2) with the experimental one in (3)

Figure 1 shows the general sketch of this research.

\section{Chemistry Reaction Mechanism}

The self-expanding polymer material is mainly constituted of isocyanate, polyhydric alcohol, blowing agent, water, and catalyst. These materials are combined with two components, called Components A and B. Component A consists of isocyanate; Component B consists of polyhydric alcohol, $\mathrm{PBA}$, water, and catalyst.

The blowing agent can be divided into physical blowing agent and chemical blowing agent according to the blowing principle. Water is the common chemical blowing agent of polymer, which reacts with isocyanate to produce carbon dioxide and promote grout polymerization as well. The commonly used physical blowing agents are CFC-11, CFC-13, HCFC-141b, C5H10, and so forth. With the increase of the grout temperature, the PBA dissolved in the polymer grout gradually vaporizes. A large number of tiny bubbles are generated and dispersed in the grout. This causes continuous grout expansion. When studying the polymer diffusion mechanism, it is necessary to calculate the number of bubbles during the foaming process in order to accurately simulate the grout expansion process $[19,20]$. Therefore, establishing an accurate solubility model of PBA in polymer grout is needful.

The chemical reaction of self-expanding polymer grout is complex, mainly including two primary reactions: gelling reaction and blowing reaction. Gelling reaction refers to the reaction between isocyanate and polyhydric alcohol to produce polyurethane, which is as follows:

$$
\begin{aligned}
& n \mathrm{NCO}-\mathrm{R}-\mathrm{NCO}+n \mathrm{HO}-\mathrm{R}^{\prime}-\mathrm{OH} \\
& \quad \longrightarrow-\left[\mathrm{O}-\mathrm{R}^{\prime}-\mathrm{O}-\mathrm{CONH}-\mathrm{R}-\mathrm{NHCO}\right]_{n}-.
\end{aligned}
$$

Ignoring the effect of molecular diffusion, its chemical reaction kinetic equation is

$$
\begin{aligned}
\frac{\mathrm{d} X_{\mathrm{OH}}}{\mathrm{dt}}= & A_{\mathrm{OH}} \exp \left(-\frac{E_{\mathrm{OH}}}{\mathrm{RT}}\right) c_{\mathrm{OH}, 0}\left(1-X_{\mathrm{OH}}\right) \\
& \cdot\left(s_{\mathrm{NCO}}-2 s_{W} X_{W}-X_{\mathrm{OH}}\right)\left[1+r_{\mathrm{BL}} \frac{\rho_{P}}{\rho_{\mathrm{BL}}}+r_{W} \frac{\rho_{P}}{\rho_{W}}\right]^{-1} .
\end{aligned}
$$

Blowing reaction exists when water is used for the chemical blowing agent of polymer grout. Water reacts with isocyanate to form carbon dioxide, and the reaction equation is

$$
2 \mathrm{R}-\mathrm{NCO}+\mathrm{H}_{2} \mathrm{O} \longrightarrow \mathrm{R}-\mathrm{NH}-\mathrm{CO}-\mathrm{NH}-\mathrm{R}+\mathrm{CO}_{2} \uparrow .
$$

The corresponding chemical reaction kinetic equation is

$$
\begin{aligned}
\frac{\mathrm{d} X_{\mathrm{W}}}{\mathrm{d} t}= & A_{\mathrm{W}} \exp \left(-\frac{E_{\mathrm{W}}}{R T}\right) c_{\mathrm{OH}, 0}\left(1-X_{\mathrm{W}}\right) \\
& \cdot\left(s_{\mathrm{NCO}}-2 s_{\mathrm{W}} X_{\mathrm{W}}-X_{\mathrm{OH}}\right)\left[1+r_{\mathrm{BL}} \frac{\rho_{\mathrm{P}}}{\rho_{\mathrm{BL}}}+r_{\mathrm{W}} \frac{\rho_{\mathrm{P}}}{\rho_{\mathrm{W}}}\right]^{-1},
\end{aligned}
$$

where $A_{\mathrm{OH}}$ and $A_{\mathrm{W}}$ are the preexponential factor, $E_{\mathrm{OH}}$ and $E_{\mathrm{W}}$ are the activation energy, $c_{i, 0}$ is the initial concentration of each component, $c_{i}$ is the current concentration of each component, and $X_{i}$ is their fractional conversion: $X_{i}=c_{i, 0}-c_{i} / c_{i, 0}, s_{\mathrm{NCO}}=c_{\mathrm{NCO}, 0} / c_{\mathrm{OH}, 0}$, and $s_{\mathrm{W}}=c_{\mathrm{W}, 0} / c_{\mathrm{OH}, 0} \cdot R$ is the universal gas constant, $T$ is the grout temperature, $r_{i}$ is the mass fraction of each component, and $\rho_{i}$ is their density $[21,22]$.

Both gelling reaction and blowing reaction are exothermic reactions. With the progress of chemical reaction, a large amount of heat energy was produced, which causes continuous temperature increase of grout system.

The polymer satisfies the following energy balance during the reaction process:

$$
\begin{aligned}
{\left[C_{\mathrm{P}}\right.} & \left.+r_{\mathrm{CO}_{2}} C_{\mathrm{CO}_{2}}+r_{\mathrm{W}} C_{\mathrm{W}}+r_{\mathrm{BG}} C_{\mathrm{BG}}+r_{\mathrm{BL}} C_{\mathrm{BL}}\right] \frac{\mathrm{d} T}{\mathrm{~d} t} \\
= & {\left[\frac{(-\Delta H)_{\mathrm{OH}} c_{\mathrm{OH}, 0}}{\rho_{\mathrm{P}}}\right] \frac{\mathrm{d} X_{\mathrm{OH}}}{\mathrm{d} t}+\left[\frac{(-\Delta H)_{\mathrm{W}} c_{\mathrm{W}, 0}}{\rho_{\mathrm{P}}}\right] \frac{\mathrm{d} X_{\mathrm{W}}}{\mathrm{d} t} } \\
& -\lambda\left(-\frac{\mathrm{d} r_{\mathrm{BL}}}{\mathrm{d} t}\right),
\end{aligned}
$$

where $C_{i}$ is the heat capacity of each component, $(-\Delta H)_{i}$ represents the heat of reaction, and $\lambda$ is the heat of evaporation.

On the macro level, the polymer grout can be regarded as a homogeneous fluid composed of three liquids and two 


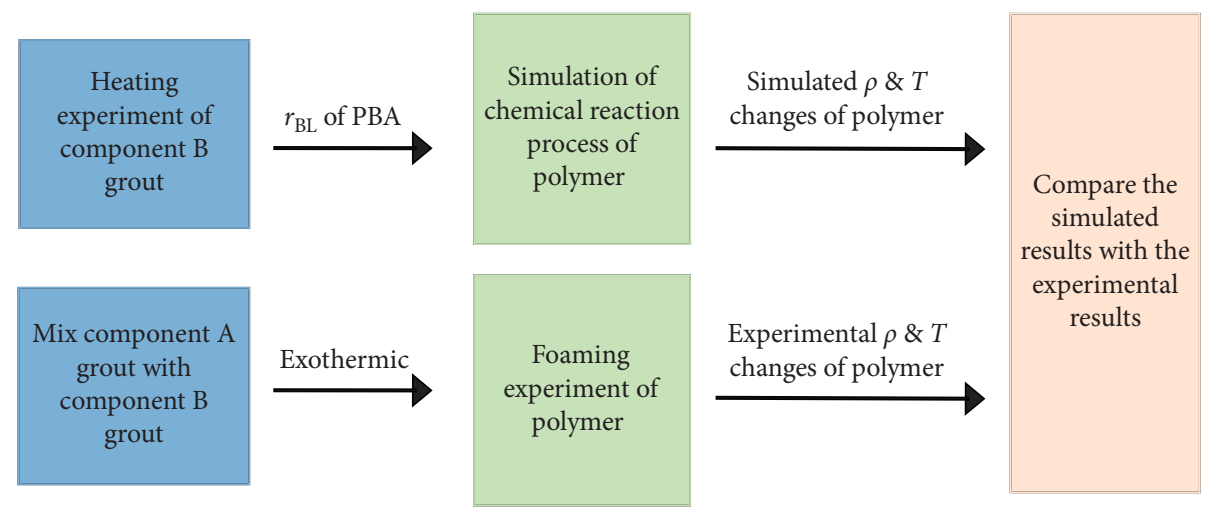

FIGURE 1: General sketch of this research.

gases. The liquid part consists of water, polyurethane, and liquid PBA. The gas part consists of gaseous PBA and carbon dioxide. The density of the polymer grout at any time is given by

$$
\rho_{F}=\frac{1+r_{\mathrm{BL}, 0}+r_{W, 0}}{r_{\mathrm{CO}_{2}} 1000 \mathrm{RT} / p M_{\mathrm{CO}_{2}}+r_{\mathrm{BG}} 1000 \mathrm{RT} / p M_{B}+r_{\mathrm{BL}} / \rho_{\mathrm{BL}}+r_{W} / \rho_{W}+1 / \rho_{P}},
$$

where $\rho_{\mathrm{BL}}$ is the density of the PBA in the liquid phase, $\rho_{\mathrm{W}}$ is the density of water, and $\rho_{\mathrm{P}}$ is the density of polyurethane. $r_{\mathrm{BL}, 0}$ and $r_{\mathrm{W}, 0}$ are the initial mass fractions of liquid PBA and water, respectively, $r_{\mathrm{BL}}$ is the current mass fraction of liquid PBA (namely, solubility of liquid PBA), $r_{\mathrm{BG}}$ is the current mass fraction of gaseous $\mathrm{PBA}$, and the relationship between $r_{\mathrm{BG}}$ and $r_{\mathrm{BL}}$ is

$$
r_{\mathrm{BG}}=r_{\mathrm{BL}, 0}-r_{\mathrm{BL}}
$$

where $r_{\mathrm{W}}$ and $r_{\mathrm{CO} 2}$ are the mass fractions of water and carbon dioxide, respectively. They can be calculated from concentration and fractional conversion, which are as follows:

$$
\begin{aligned}
r_{\mathrm{W}} & =\frac{c_{\mathrm{W}} M_{\mathrm{W}}}{1000 \rho_{\mathrm{P}}}, \\
r_{\mathrm{CO}_{2}} & =\frac{c_{\mathrm{W}, 0} X_{\mathrm{W}} M_{\mathrm{CO}_{2}}}{\left(1000 \rho_{\mathrm{P}}\right)-r_{\mathrm{CO}_{2}, \mathrm{D}}},
\end{aligned}
$$

where $M_{\mathrm{i}}$ is the molecular weight and $r_{\mathrm{CO} 2 \mathrm{D}}$ is the initial mass fraction of carbon dioxide.

It can be seen from equation (6) that the density equation is closely related to $r_{\mathrm{BG}}$ and $r_{\mathrm{BL}}$. This further proved the significance of obtaining an accurate PBA solubility model for solving the polymer expansion process.

\section{Test Method}

Assuming that the PBA solubility in Component $B$ is the same as that in the mixture of Components $A$ and $B$, in order to eliminate the interference of carbon dioxide caused by blowing reaction, the solubility test was carried out in Component B grout.
The changes of grout volume and temperature with respect to time were obtained by heating Component $\mathrm{B}$ grout. The volume change, as well as the volume of PBA, can be calculated as follows:

$$
\Delta V(t)=V(t)-V_{0},
$$

where $\Delta V(t)$ is the volume of the $\mathrm{PBA}$ at time $t, V_{0}$ is the initial volume of Component $\mathrm{B}$, and $V(t)$ is the measured volume of Component B at time $t$.

The Ideal Gas Law was put forward by Clapeyron in 1834 , and the equation is

$$
p V=n R T
$$

where $p$ is atmospheric pressure, $R$ is the universal gas constant with $8.31 \mathrm{~J} /(\mathrm{mol} \cdot \mathrm{k})$, and $T$ is the temperature.

The mole number of the gaseous PBA can be calculated from equation (10) with $T(t)$ and $\Delta V(t)$, which were obtained previously.

The mass of the gaseous PBA at time $t$ is obtained as follows:

$$
m_{\mathrm{BG}}=n(t) \times M_{B}
$$

where $n(t)$ is the mole number and $M_{\mathrm{B}}$ is the molecular weight of PBA.

Since the total mass of the PBA remains constant, the mass of the liquid PBA dissolved in Component $\mathrm{B}$ at time $t$ can be obtained with

$$
m_{\mathrm{BL}}=m_{\mathrm{B}}-m_{\mathrm{BG}}
$$

Given the total mass of Component B grout with $m$, the solubility of the PBA at time $t$ can be calculated as 


$$
r_{\mathrm{BL}}=\frac{m_{\mathrm{BL}}}{m-m_{\mathrm{B}}}
$$

where $m_{\mathrm{B}}$ is the total mass of the PBA and $m_{\mathrm{BL}}$ is the mass of the PBA in the liquid phase.

By repeating the above steps, the solubility of the PBA with corresponding temperature at each moment can be calculated, so as to obtain the solubility curve of the PBA with the change of temperature [23].

\section{Test Process}

In order to test the solubility curve of the PBA, the heating and testing device of PBA is designed, as shown in Figure 2. The testing device consists of graduated metal measuring cylinder, the temperature sensor, the induction cooker, and so on. Component B grout was heated by the electromagnetic heating. The grout temperature increased after heating. The PBA vaporized and formed tiny bubbles distributed in the grout, which caused the progressively grout expansion.

The test of the solubility model of the PBA is mainly divided into the following steps:

(i) Inject Component B grout into a graduated metal measuring cylinder.

(ii) Turn on the induction cooker; the metal measuring cylinder generates heat energy with the electromagnetic effect, which causes the expansion of Component B grout.

(iii) Use the temperature sensor to read and record the temperature value of Component $B$ grout during the heating process.

(iv) Read the height of the grout level of Component B on the measuring cylinder at the same time; the volume value of Component B grout can be calculated according to the height value.

(v) Calculate the solubility of PBA corresponding to the temperature according to the recorded temperature and volume value; thus, the solubility model is obtained.

The conditions of the used polymer grout are as follows.

At the initial moment, the mass of the PBA in Component $\mathrm{B}$ grout is $7.2 \mathrm{~g}$, the molecular weight of the $\mathrm{PBA}$ is $116.9 \mathrm{~g} / \mathrm{mol}$, the mass of Component B grout is $372 \mathrm{~g}$, the initial temperature is $299.65 k$, the volume of Component B grout is $150 \mathrm{~cm}^{3}$, and the standard atmospheric pressure is $1.01325 \times 10^{5} \mathrm{~Pa}$.

Figure 3 shows the volume and temperature variations of Component $\mathrm{B}$ grout at different times. It can be seen that, with the continuous temperature decrease, Component $\mathrm{B}$ grout expands constantly. This indicates that, during the heating process, the vaporized PBA inside Component B leads to the bubble formation and the grout expansion.

The grout is estimated to be composed of a cylindrical base and half of an oblate ellipsoid of revolution. Based on this characteristic, Ireka et al. [24] proposed a calculation method of grout volume, as shown in the following equation:

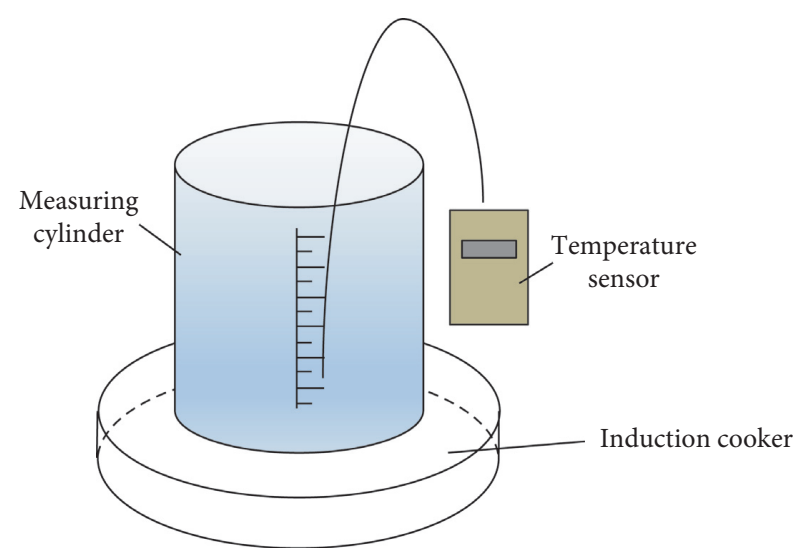

Figure 2: Heating and testing device.

$$
V(t)=\pi R^{2} h_{1}(t)+\frac{2}{3} \pi R^{2}\left[h(t)-h_{1}(t)\right],
$$

where $R$ is the radius, $h(t)$ is the height from the bottom to the highest point of the liquid level, and $h_{1}(t)$ is the height of cylindrical base.

Figure 4 shows the schematic diagram of how to read the grout height.

The temperature change of Component B grout is displayed in Figure 5; it is obvious that the grout temperature increases as time goes on.

Figure 6 shows the variation of volume with respect to time of Component B grout. The volume of grout increases slowly from $0 \mathrm{~s}$ to $150 \mathrm{~s}$. After $150 \mathrm{~s}$, the volume increases rapidly and gradually slows down.

The curve of Component B grout volume change with respect to the change of temperature was obtained according to the method of part two, which is plotted in Figure 7. It shows that the grout volume expands slowly at the beginning and tends to be fast when the temperature reaches about $360 k$.

Figure 8 is the calculation curve of the PBA with respect to the temperature change. The points and the curves represent the real experimental value and the fitting value, respectively. At the initial moment, the solubility of the PBA decreases slowly with the increase of temperature. When the temperature is greater than about $360 k$, the solubility starts to decrease rapidly.

The fitting curve, which is shown in Figure 7, was fitted with the experimental data. The curve can be expressed by the following formula:

$$
r_{\mathrm{BL}}= \begin{cases}a T+b, & T<361.95, \\ c T^{2}+d T-e, & 361.95 \leq T \leq 389.35, \\ 0, & T>389.35,\end{cases}
$$

where $a=-2.67781 \times 10^{-5}, b=0.02725, c=-7.26908 \times 10^{-6}$, $d=0.00478$, and $e=0.75947$.

\section{Applicability Verification}

The following steps were applied to verify the solubility model of the PBA: 


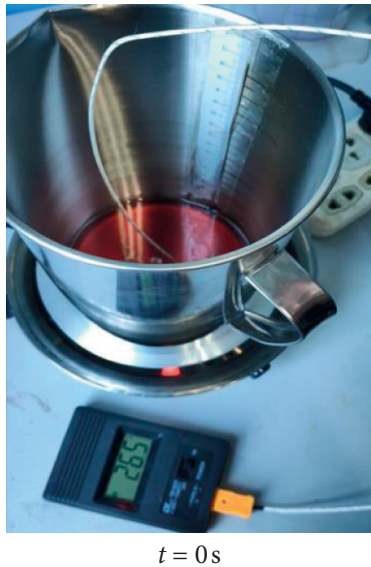

(a)

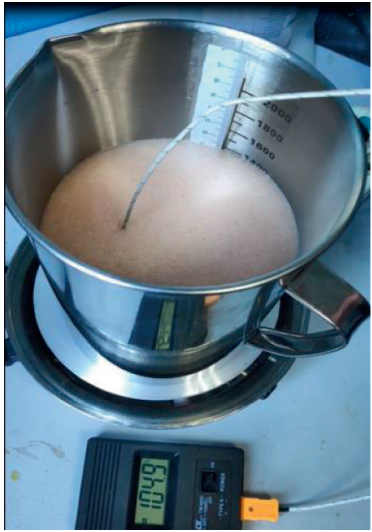

$t=227 \mathrm{~s}$

(d)

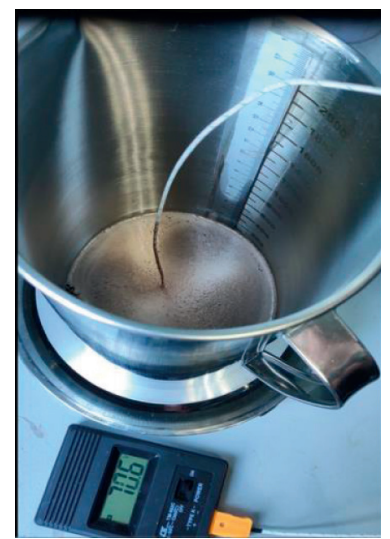

$t=147 \mathrm{~s}$

(b)

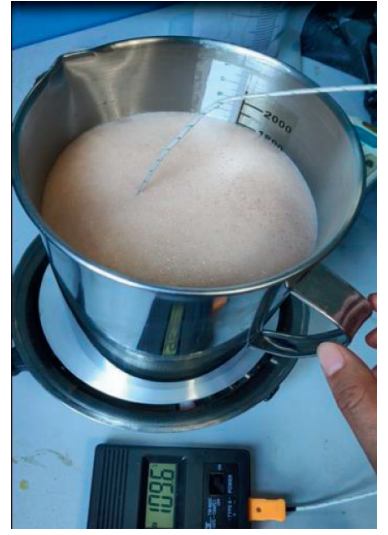

(e)

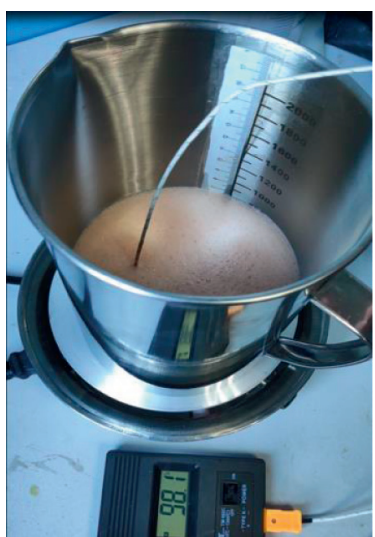

$t=206 \mathrm{~s}$

(c)

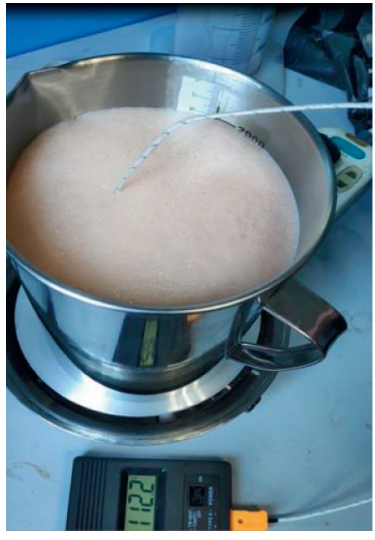

$t=266 \mathrm{~s}$

(f)

Figure 3: The volume and temperature changes of Component B grout at different times.

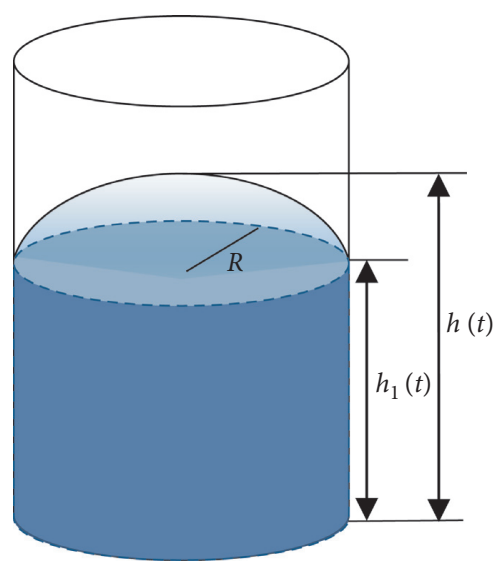

Figure 4: The schematic diagram of grout volume reading.

(i) Carry out the foaming experiment of self-expanding polymer grout to obtain its temperature and volume changes with respect to time.

(ii) Obtain the curve of the polymer density change with respect to time according to the volume change.

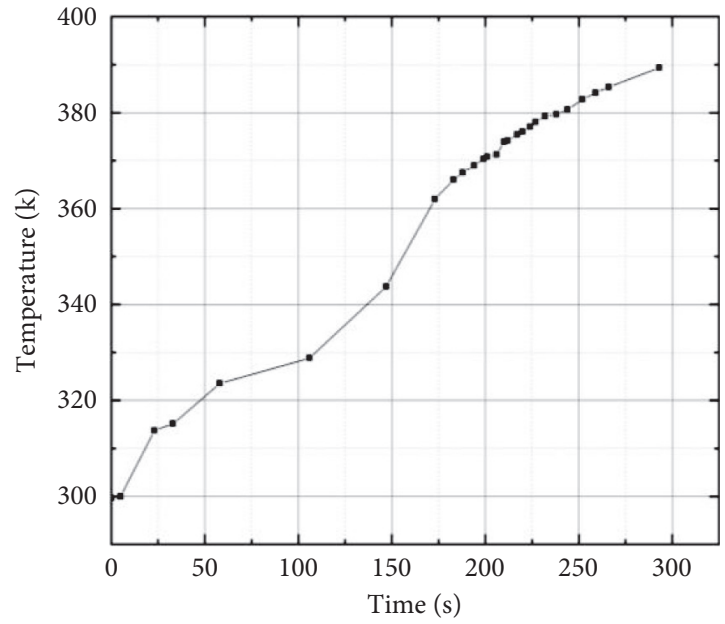

FIGURE 5: The temperature change curve with respect to time of the Component B grout.

(iii) Use the solubility curve of PBA to simulate the chemical reaction process of polymer. The calculated value of polymer temperature and density changes are gained according to simulation. 


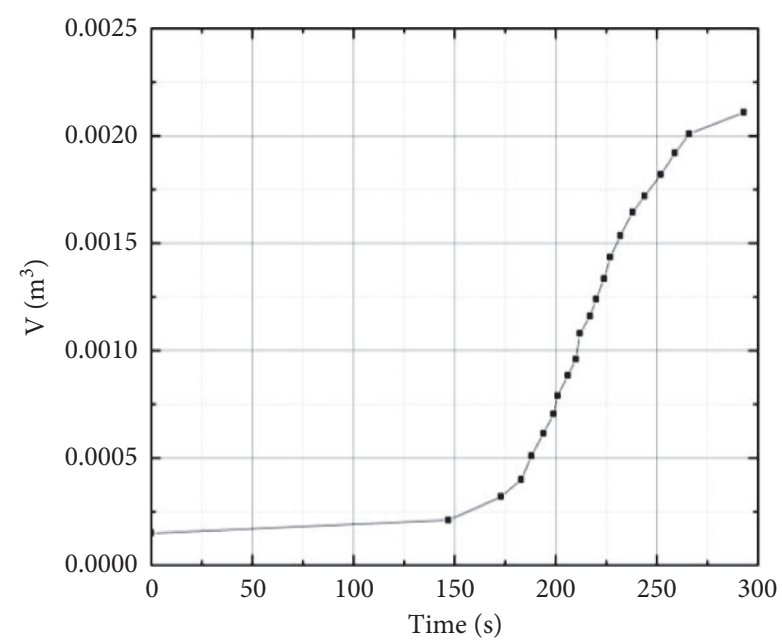

Figure 6: The volume change curve with respect to time of the Component B grout.

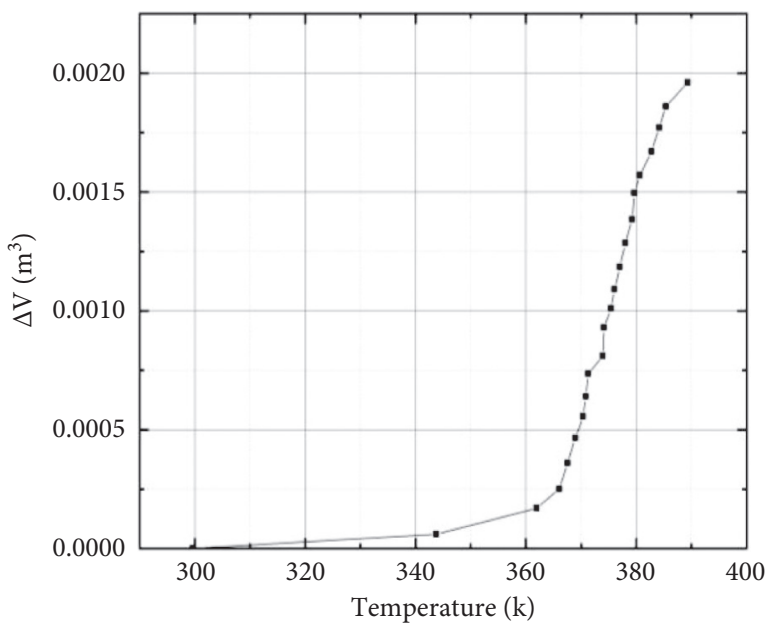

Figure 7: The volume change curve of Component B grout with respect to the temperature change.

(iv) Compare the calculated temperature and density variations with the corresponding experimental results, respectively. The measured solubility curve of the PBA can be judged to be applicable if the deviations are small.

The two-component polymer foaming experiment was carried out in a graduated measuring cylinder. Before starting the experiment, the measuring cylinder was placed on an electronic scale. The temperature sensor was placed inside the measuring cylinder. After a certain amount of polymer grout was injected into the measuring cylinder, the chemical reaction of the polymer grout occurred. The liquid height and the polymer temperature were recorded at different times. The grout volume was calculated according to the liquid height with equation (13). The corresponding density value could be obtained with the grout volume.

The foaming process was recorded in real time, as shown in Figure 9. It can be seen that the polymer begins to expand rapidly after a few seconds of injection. The grout temperature increases quickly as well. After about $60 \mathrm{~s}$, both the

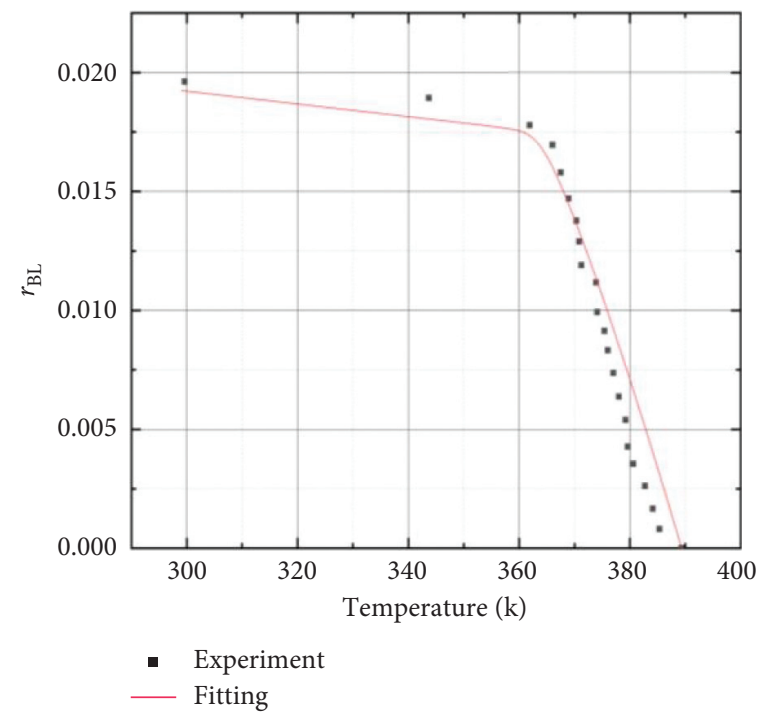

Figure 8: The solubility curve of the PBA with respect to the temperature change.

rates of grout expansion and the temperature increase slow down and eventually become stable. The polymer mass remains almost constant during the reaction process, which is obvious in Figure 8. It indicates that the vaporized PBA is still located in the mixture and does not overflow.

The reaction process of two-component polymer grout was then simulated numerically. Relevant parameters required for numerical simulation are listed in Table 1 . The numerical code was written by using the programming language, Fortran.

The reaction temperature of the self-expanding polymer grout was calculated by considering the formulas of two chemical reaction kinetics equations with equations (2) and (4) and the energy balance equation with equation (5). The Runge-Kutta method was adopted to calculate the equation set. The formula of polymer density is a function of temperature, which is shown in equation (6). Therefore, the polymer density at a certain time could be obtained after the polymer reaction temperature was figured out. 


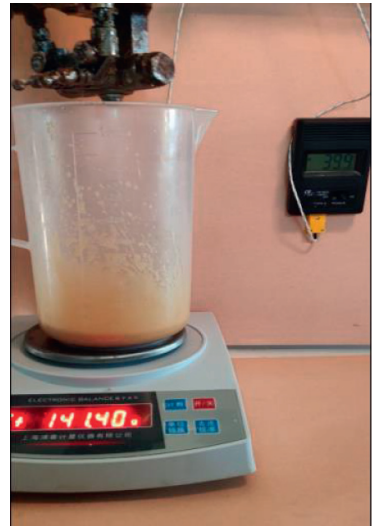

$t=5 \mathrm{~s}$

(a)

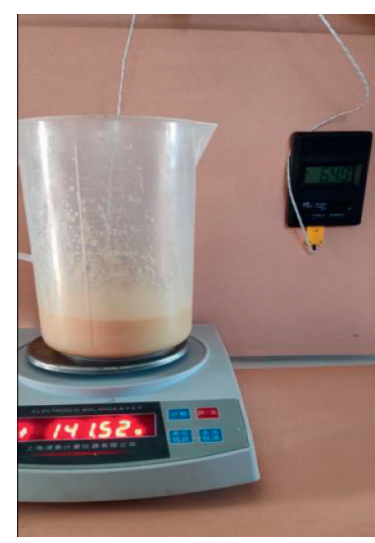

$t=18 \mathrm{~s}$

(b)

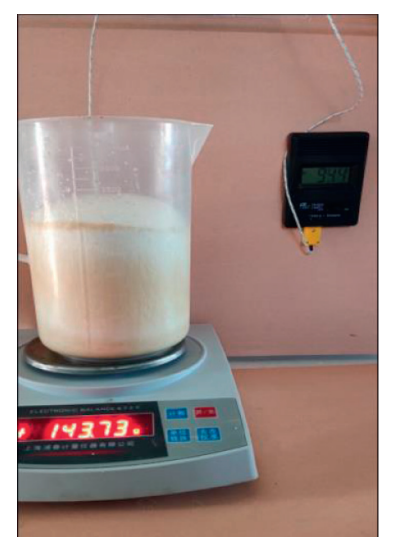

$t=26 \mathrm{~s}$

(c)

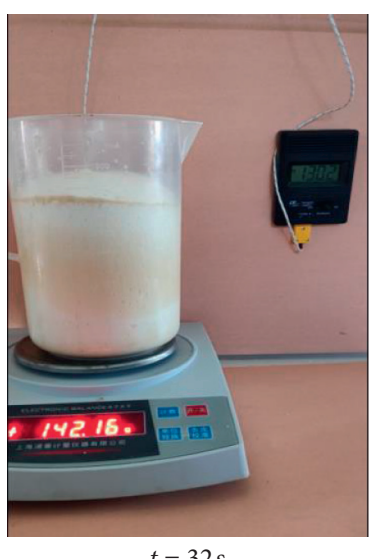

(d)

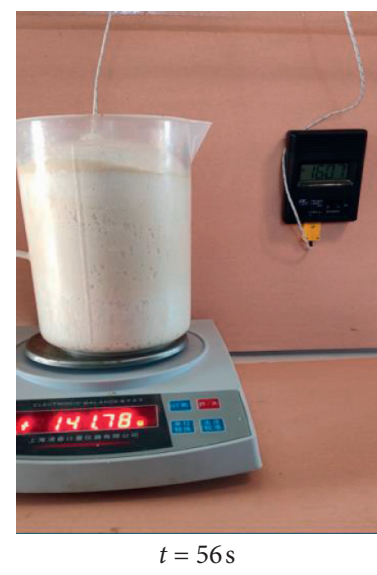

(e)

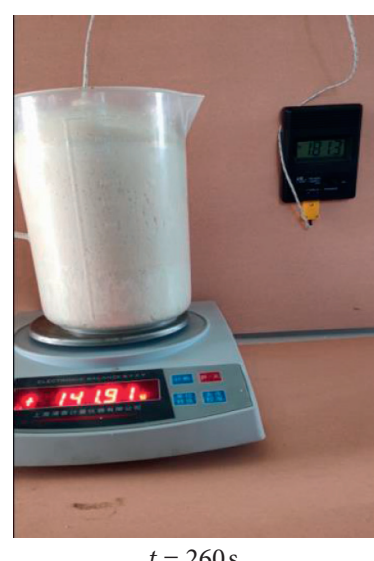

(f)

FIGURE 9: The temperature and volume changes of polymer grout at different times.

TABLE 1: Relevant parameters required for numerical simulation.

\begin{tabular}{lccc}
\hline Parameter & Value & Parameter & Value \\
\hline$c_{\mathrm{OH}, 0}\left(\mathrm{~mol} \cdot \mathrm{m}^{-3}\right)$ & 4079.6 & $C_{\mathrm{P}}(\mathrm{J} / \mathrm{kg} \cdot \mathrm{k})$ & 1800 \\
$c_{\mathrm{NCO}, 0}\left(\mathrm{~mol} \cdot \mathrm{m}^{-3}\right)$ & 4557.7 & $C_{\mathrm{CO} 2}(\mathrm{~J} / \mathrm{kg} \cdot \mathrm{k})$ & 836.6 \\
$c_{\mathrm{W}, 0}\left(\mathrm{~mol} \cdot \mathrm{m}^{-3}\right)$ & 294.7 & $C_{\mathrm{BL}}(\mathrm{J} / \mathrm{kg} \cdot \mathrm{k})$ & 1159 \\
$T_{0}(k)$ & 300.75 & $C_{\mathrm{BG}}(\mathrm{J} / \mathrm{kg} \cdot \mathrm{k})$ & 1000 \\
$A_{\mathrm{OH}}\left(\mathrm{m}^{3} \cdot \mathrm{s}^{-1} \cdot \mathrm{mol}^{-1}\right)$ & 2.7029 & $C_{\mathrm{W}}(\mathrm{J} / \mathrm{kg} \cdot \mathrm{k})$ & 4200 \\
$A_{\mathrm{W}}\left(\mathrm{m}^{3} \cdot \mathrm{s}^{-1} \cdot \mathrm{mol}^{-1}\right)$ & 26.54 & $\rho_{\mathrm{P}}\left(\mathrm{kg} / \mathrm{m}^{3}\right)$ & 1100 \\
$E_{\mathrm{OH}}\left(\mathrm{J} \cdot \mathrm{mol}^{-1} \cdot \mathrm{k}^{-1}\right)$ & 35195.707 & $\rho_{\mathrm{BL}}\left(\mathrm{kg} / \mathrm{m}^{3}\right)$ & 1228 \\
$E_{\mathrm{W}}\left(\mathrm{J} \cdot \mathrm{mol}^{-1} \cdot \mathrm{k}^{-1}\right)$ & 42046.74 & $M_{\mathrm{B}}(\mathrm{g} / \mathrm{mol})$ & 116.90 \\
$(-\Delta H)_{\mathrm{OH}}\left(\mathrm{J} \cdot \mathrm{mol}^{-1}\right)$ & 77050 & $M_{\mathrm{CO} 2}(\mathrm{~g} / \mathrm{mol})$ & 44 \\
$(-\Delta H)_{\mathrm{W}}\left(\mathrm{J} \cdot \mathrm{mol}^{-1}\right)$ & 86000 & $r_{\mathrm{BL}, 0}$ & 0.0196 \\
\hline
\end{tabular}

Figure 10 shows the experimental and simulated results of polymer grout temperature during the reaction process. The polymer grout temperature increases sharply at the beginning of the reaction and then slows down. The simulated temperature is higher than that of experiment from about $25 \mathrm{~s}$, but it gradually reaches agreement with the experimental result later. At around $45 \mathrm{~s}$, the difference value reaches the maximum point; however, the error between the two is still within $2 \%$. The simulated value is in good agreement with the experimental value, which proves the accuracy of the solubility model.

The comparison between the experimental value and the simulated value of polymer density is shown in Figure 11. Before about $20 \mathrm{~s}$, the polymer density drops quickly, and it tends to be stable after that. The experimental and simulated curves are in a similar trend with respect to time. However, the calculated density is a little bit greater than the experimental value from $15 \mathrm{~s}$ to $25 \mathrm{~s}$. The biggest error between the 


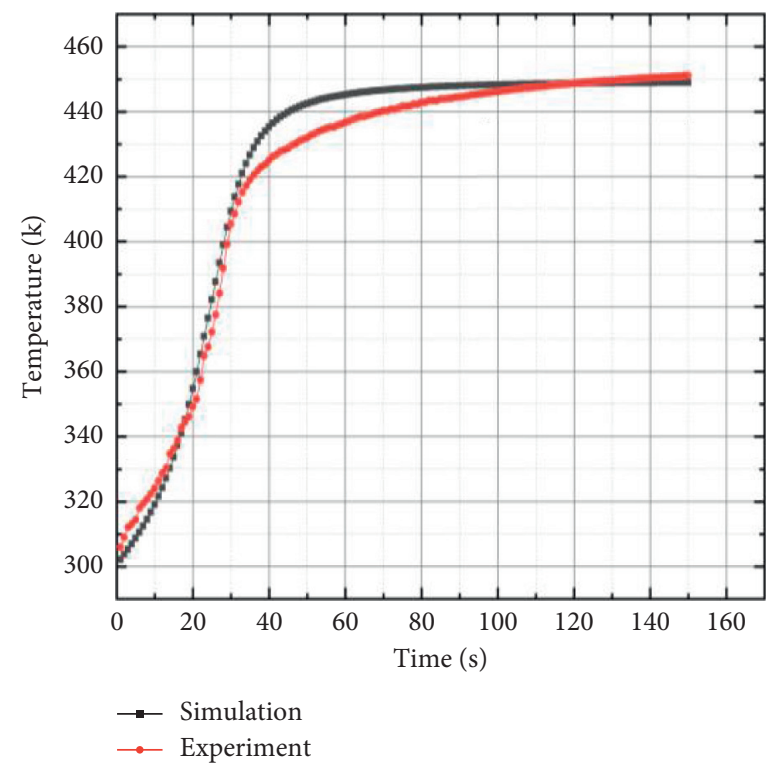

Figure 10: Comparison of the polymer reaction temperature.

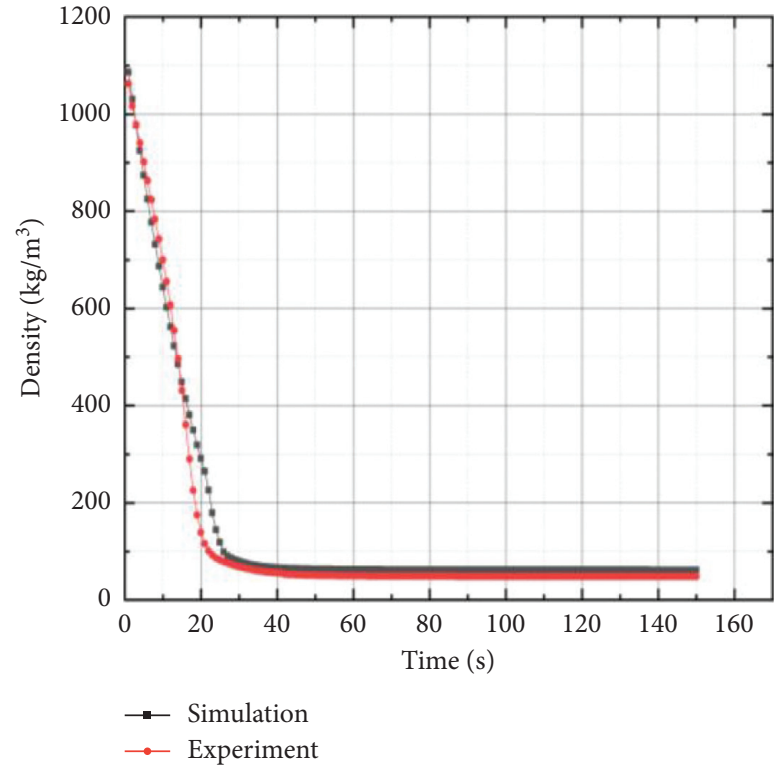

FIGURE 11: Comparison of the polymer density.

two is $5 \%$ at around $25 \mathrm{~s}$. In general, the numerical simulation result is close to the experimental result, which further illustrates the applicability of the solubility model.

\section{Summary and Conclusions}

An accurate solubility model of PBA is the prerequisite for studying the diffusion mechanism of self-expanding polymer grout. The main work and conclusion are summarized as follows:

(1) This paper provides a fast and effective way to accurately obtain the PBA solubility model and its verification process of polymer, which is more complete than the previous researches.
(2) The experiment of two-component polymer grout was carried out to test the temperature and density changes during the grout expansion process. The temperature and density values obtained by the simulation are compared with the experimental values. The error between the simulated and experimental values is within $5 \%$, which verifies the applicability of the solubility model.

(3) As can be seen from the comparison figures (Figures 10 and 11), some biases still exist. The main reason for this phenomenon comes from the error of heating experiment of Component B grout.

(4) The solubility of different PBAs in the grout composed with different raw materials is different. In this 
paper, only one of the commonly used polymers has been studied. Further experiments of variety polymers should be conducted to improve this research.

(5) The research lays a theoretical foundation for both the simulation analysis of diffusion polymer process and the grouting mechanism study.

\section{Nomenclature}

$\begin{array}{ll}A_{i}: & \text { Preexponential factor } \\ E_{i}: & \text { Activation energy } \\ c_{i, 0}: & \text { Initial concentration } \\ c_{i}: & \text { Current concentration } \\ X_{i}: & \text { Fractional conversion } \\ R: & \text { Universal gas constant } \\ T: & \text { Grout temperature } \\ r_{i}: & \text { Mass fraction } \\ \rho_{i}: & \text { Density } \\ C_{i}: & \text { Heat capacity } \\ (-\Delta H)_{i}: & \text { Heat of reaction } \\ \lambda: & \text { Heat of evaporation } \\ M_{i}: & \text { Molecular weight } \\ p: & \text { Atmospheric pressure } \\ V_{i}: & \text { Volume } \\ n: & \text { Mole number } \\ m_{i}: & \text { Mass } \\ h_{i}: & \text { Height } \\ \text { Indices } & \\ \mathrm{OH}: & \text { Hydroxyl group } \\ \mathrm{W}: & \text { Water } \\ \mathrm{CO}: & \text { Carbon dioxide } \\ \mathrm{NCO}: & \text { Cyanate group } \\ \mathrm{BL}: & \text { Liquid phase of physical blowing agent } \\ \mathrm{BG}: & \text { Gas phase of physical blowing agent } \\ \mathrm{B}: & \text { Physical blowing agent } \\ \mathrm{P}: & \text { Polyurethane } \\ \mathrm{F}: & \text { Polymer grout foam. } \\ & \end{array}$

\section{Data Availability}

The data used to support the findings of this study are available from the corresponding author upon request.

\section{Conflicts of Interest}

The authors declare that they have no conflicts of interest.

\section{Acknowledgments}

This research was supported by the National Key Research and Development Plan (Grant nos. 2017YFC0504503 and 2018YFB1600200), the Program for Science and Technology Innovation Talents in Universities of Henan Province (Grant no. 19HASTIT041), the National Natural Science Foundation of China (Grant nos. 51908514, 51878624, 51878622, and U1404525), the Natural Science Foundation of Henan Province (Grant no. 202300410746), Henan Science Fund for Distinguished Young Scholars (Grant no. 202300410354), Postdoctoral Research Sponsorship in
Henan Province (Grant no. 19030026), and Major Scientific and Technological Special Project in Henan (Grant no. 181100310400).

\section{References}

[1] D. Klempner, Handbook of Polymeric Foams and Foam Technology, Hanser Publishers, Munich, Germany, 2nd edition, 2004.

[2] G. Gustafson and H. Stille, "Stop criteria for cement grouting," Felsbau, vol. 23, no. 3, pp. 62-68, 2005

[3] L. R. Shucai, "Protection against water or mud inrush in tunnels by grouting: a review," Journal of Rock Mechanics and Geotechnical Engineering, vol. 8, no. 5, pp. 753-766, 2016.

[4] R. Pusch and Knutsson, "Study of cement-grout penetration into fractures under static and oscillatory conditions," Tunnelling \& Underground Space Technology, vol. 45, pp. 10-19, 2015.

[5] W. H. Lee, S. W. Lee, T. J. Kang, K. Chung, and J. R. Youn, "Processing of polyurethane/polystyrene hybrid foam and numerical simulation," Fibers and Polymers, vol. 3, no. 4, pp. 159-168, 2002.

[6] H. Z. Saboorian-Jooybari, Z. M. Dejam, and Z. Chen, "Heavy oil polymer flooding from laboratory core floods to pilot tests and field applications: half-century studies," Journal of Petroleum Science and Engineering, vol. 142, pp. 85-100, 2016.

[7] B. Zhang, L. Wang, and M. Hao, "An analytical solution for the radial flow of variable density grout in rock fractures," Construction and Building Materials, vol. 206, no. 10, pp. 630-640, 2019.

[8] J. M. Castro, "Studies of mold filling and curing in the reaction injection molding process," AICHE Journal, vol. 28 , no. 2 , pp. 250-260, 1982.

[9] L. Wang, M. Hao, and Y. Zhong, "A quasi-3D numerical model for grout injection in a parallel fracture based on finite volume method," Complexity, vol. 2019, no. 3, 18 pages, Article ID 4139616, 2019.

[10] C. Qian, S. J. Mumby, and B. E. Eichinger, "Phase diagrams of binary polymer solutions and blends," Macromolecules, vol. 34, no. 12, pp. 2540-2545, 1991.

[11] R. Tesser, M. Di Serio, A. Sclafani et al., "Modeling of polyurethane foam formation," Journal of Applied Polymer Science, vol. 92, no. 3, pp. 1875-1886, 2004.

[12] E. Santacesaria, M. D. Serio, and R. Gargiulo, "Vapour-liquid equilibrium measurements for binary mixtures of R32, R143a, R134a and R125 with a perfluoropolyether lubricant," Journal of Fluorine Chemistry, vol. 121, no. 1, pp. 15-22, 2003.

[13] E. Santacesaria, A. Passaretti, and M. Di Serio, "Phase equilibria in binary mixtures refrigerant + fluorinated lubricating oil: vapor-Liquid and Liquid-Liquid measurements," Journal of Chemical \& Engineering Data, vol. 49, no. 4, pp. 838-846, 2004.

[14] E. Santacesaria, E. Musso, and M. D. Serio, "Description of the vapor-liquid equilibrium in binary refrigerant/lubricating oil systems by means of an extended Flory-Huggins model," Journal of Fluorine Chemistry, vol. 99, no. 1, pp. 29-36, 1999.

[15] V. K. Gupta and D. V. Khakhar, "Formation of integral skin polyurethane foams," Polymer Engineering \& Science, vol. 39, no. 1, pp. 164-176, 1999.

[16] S. M. Geier, M. C. Winkler, and M. Piesche, "Numerical simulation of mold filling processes with polyurethane foams," Chemical Engineering \& Technology, vol. 32, no. 9, pp. 1438-1447, 2009. 
[17] A. J. Rojas, J. H. Marciano, and R. J. Williams, "Rigid polyurethane foams: a model of the foaming process," Polymer Engineering and Science, vol. 22, no. 13, pp. 840-844, 1982.

[18] D. J. R. Seo and J. R. Youn, "Numerical analysis on reaction injection molding of polyurethane foam by using a finite volume method," Polymer, vol. 46, no. 17, pp. 6482-6493, 2005.

[19] S. A. Baser and D. V. Khakhar, "Modeling of the dynamics of R-11 blown polyurethane foam formation," Polymer Engineering \& Science, vol. 34, no. 8, pp. 632-641, 1994.

[20] S. A. Baser and D. V. Khakhar, "Modeling of the dynamics of water and R-11 blown polyurethane foam formation," Polymer Engineering and Science, vol. 34, no. 8, pp. 642-649, 1994.

[21] J. Kosek, M. Karimi, and D. L. Marchisio, "Multi-scale modelling of expanding polyurethane foams: coupling macroand bubble-scales," Chemical Engineering Science, vol. 148, pp. 55-64, 2016.

[22] S. D. Lipshitz and C. W. Macosko, "Kinetics and energetics of a fast polyurethane cure," Journal of Applied Polymer Science, vol. 21, no. 8, pp. 2029-2039, 1977.

[23] M. D. L. Karimi and D. L. Marchisio, "A baseline model for the simulation of polyurethane foams via the population balance equation," Macromolecular Theory and Simulations, vol. 24, no. 4, pp. 291-300, 2015.

[24] I. E. Ireka, D. Niedziela, J. S. K. TröltzschSchäfer, F. Helbig, T. Chinyoka, and L. Kroll, "Computational modelling of the complex dynamics of chemically blown polyurethane foam," Physics of Fluids, vol. 27, no. 11, pp. 113102-113192, 2015. 